\title{
ONLINE KNOWLEDGE-BASED EXPERT SYSTEM (KBES) FOR PSYCHOLOGICAL DisEASES DIAGNOSIS
}

\author{
Ahmad A. Al-Hajji ${ }^{1}$, Fatimah M. AlSuhaibani ${ }^{2}$ and Nouf S. AlHarbi ${ }^{3}$ \\ ${ }^{1,2,3}$ Department of Computer Science, College of Science \& Arts in Al- \\ Bukairyah, \\ Qassim University, Saudi Arabia
}

\begin{abstract}
Artificial Intelligence (AI) is one of computer science branches and is used to solve problems with symbolic reasoning. Expert systems (ESs) are one of the prominent research domains of AI. We developed declarative, online procedural rule-based expert system models for psychological diseases diagnosis and classification. The constructed system exploited computer as an intelligent and deductive tool. This system diagnoses and treats more than four types of psychiatric diseases, i.e., depression, anxiety disorder, obsessive-compulsive disorder, and hysteria. The system helps psychology practitioner and doctors to diagnose the condition of a patient efficiently and in short time. It is also very useful for the patients who cannot go to a doctor because they cannot afford the cast, or they do not have a psychological clinic in their area, or they are ashamed of discussing their situation with a doctor. The system consists of program codes that make a logic decision to classify the problem of the patient. The methodology for developing the declarative model was based on the backward chaining, also called goal-driven reasoning, where knowledge is represented by a set of IF-THEN production rules. The declarative programs were written in the PROLOG. While the design of the procedural model was based on using common languages like PHP, JavaScript, CSS, and HTML. The user of the system will enter the symptoms of the patients through the user interface and the program executes. Then the program links the symptoms to the pre-programmed psychological diseases, and will classify the disease and recommend treatment.
\end{abstract}

The proposed online system link: http:/lesp-online.site/

\section{KEYWORDS}

Artificial Intelligence, Expert systems, Medical Diagnosis, Rules, Symbolic Reasoning

\section{INTRODUCTION}

Expert systems (ESs) belong to the class of artificial intelligence systems. ESs are complex software, which accumulate knowledge of specialists in a specific problem domain and replicating this empirical experience to consult less qualified users. Our vision is to spread the use of computer technology in the field of medical psychology to contribute to the advancement of this field. So, the proposed system is not widely implemented. Psychiatric diseases are not related to the mental and cultural development of the human being, but is mainly the result of events experienced by humans in their lives, and in many cases are painful, difficult and complex events, making him unable to solve any problem in his life, and thus exacerbate these problems and Psychiatric patients suffering from depression [1]. We tried as much as possible to explore in a deep and careful way to learn more about Psychiatric diseases to do our great research and answer questions about this disorder and will limit the content as much as possible to the following five

Dhinaharan Nagamalai et al. (Eds) : COSIT, AIAPP, DMA, SEC - 2019

pp. 57-71, 2019. (C) CS \& IT-CSCP 2019

DOI: $10.5121 /$ csit.2019.90206 
common types of psychiatric diseases: Depression, anxiety disorder, obsessive-compulsive disorder, and hysteria [2]. There are several factors for these Psychiatric diseases, most notably: Biological factors such as heredity, prenatal damage, infection, diseases and toxins, brain injury and congenital disabilities. Life experiences and environmental factors such as life events and emotional stress, parental abuse, and neglect, social expectations, and appreciation, poverty and societies, and cultures [3]. The purpose of this paper is create an application (Rule-Based Expert System) and to get a better understanding of exactly what expert systems do, how they are set up, and how expert system rules tend to work. The generalized structure of the expert system is presented in Figure 1. It should be noted that existing ES could have a more complex structure; however, the elements shown in this figure are an integral part of any ES. The knowledge base $(\mathrm{KB})$ is the core of the ES. One of the main characteristics of this system is that in parallel to the knowledge base of the traditional expert system a database exists with information about the present state of the process that interacts with the knowledge base of the system. This database is in a state of continuous change. The knowledge base of the system contains both analytical knowledge and heuristic knowledge about the process [4].

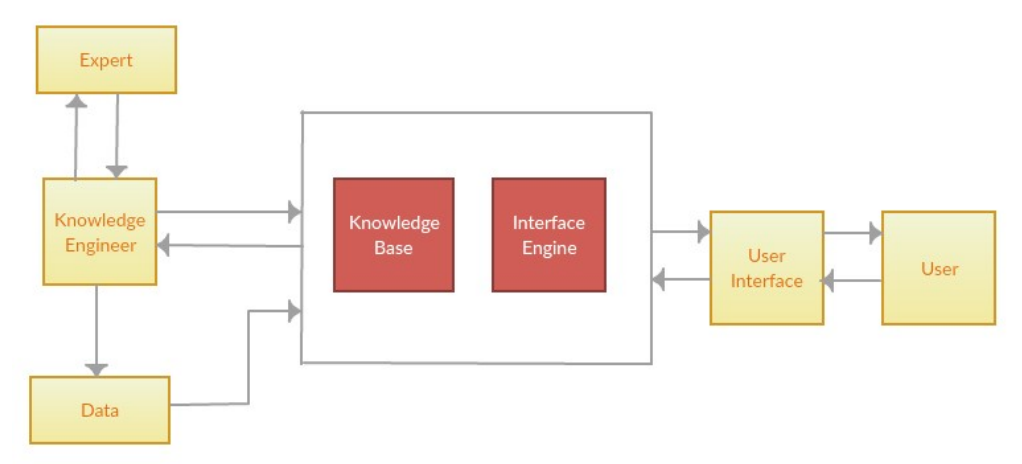

Figure 1: The generalized structure of an expert system

The knowledge engineering task comprises different knowledge sources and structures. The inference engine combines heuristic reasoning with algorithmic operation in order to reach a specific conclusion. Response time is a critical issue for online expert systems because they are operating in parallel with a dynamic process [5]. The user interface is a set of programs that implement the dialogue between the end user and the ES both at the stage of entering information and when receiving results.

\section{ObJectives of The Proposed System}

Following were the main objectives of the proposed expert system:

- Help the people by providing them the technology to keep in contact with their doctor or hospital, especially in the emergency;

- Design and development of an online system for diagnosing psychiatric disorders;

- Allowing the patient to recognize the symptoms of the disease he complains about;

- Use advanced software and scripting languages to make the online system more flexible and easy to interact and understand;

- Design and build a knowledge base that contains details of psychiatric diseases. 


\section{RELATED WORK}

The medical expert systems have tolerated many changes and are using modern techniques to produce optimal outputs. It has been generally observed in various references that psychiatric diagnosis systems are based on information collected from patients.

Ahmad A, Al-Hajji [6] developed a Rule-Based Expert System for Neurological Diseases. The proposed system supports both physicians and patients with the possibility of diagnosing more than 10 types of common neurological diseases through the design of an attractive graphical interface that simulates the expert system shell.

Komal R. Hole, Vijay S. Gulhane [7] presented an Rule-based Expert System for Memory Loss Disease. This paper included the collection of information on memory loss, symptoms of memory loss and its causes by different age groups. Also, a case-based medical expert system model for the diagnosis of memory loss disease was developed. For this reason, four types of neurological diseases have been covered, i.e., Alzheimer Disease, Dementia, Parkinson Disease, Huntington Disease.

Based on the Diagnostic and Statistical Manual of Mental Disorders (DSM-IV), the references [8], [9]. [10] have developed lists of various symptoms of mental illness, that help doctors to increase the accuracy of diagnosis of these diseases, which will positively affect the condition of patients.

Dr. D.K. Sreekantha, T.M. Girish and Dr. R.V.Kulkarni [11] presented a study on knowledgebase systems in neuro science, in order to survey the soft computing techniques used in the treatment of neurological problems around the world.

Badri Adhikari, Md. Hasan Ansari, Priti Shrestha and Susma Pant [12] have developed an expert neurological diagnostic system on the Internet to help doctors diagnose nerves. Where doctors can use the website as a useful tool to diagnose their patients, using rules and cases to achieve the goal of decision-making for field experts.

Borgohain, Rajdeep, and Sugata Sanyal [13] discussed the implementation of an expert-based system for the diagnosis of neurological and muscular diseases. In this system, a list of questionnaires about patients' symptoms is presented and accordingly, the disease is diagnosed and possible treatment is suggested. The system can help and support patients with neurological and muscular diseases to get an idea of their disease and possible treatment methods.

Luciano Comin Nunes, Plácido Rogério Pinheiro, Tarcísio Cavalcante Pequeno [14] presented a study aimed at making proactive decisions to adopt measures based on early diagnosis of mental disorders. Thus, it presents a proposal for some specialist system organization methodologies to support the resolution and structured representation of knowledge in the production possibilities and rules.

The book chapter [15] includes a short survey on the use of IT applications in psychology and psychiatry. Where more multidisciplinary research is being conducted in this area. The proposed system aims to increase the expert's potential by developing new methods of information finding, including application of artificial intelligence (AI) with specific HCI techniques. 


\section{Methodology of the Proposed System}

In this paper, it has been designed a declarative, as well as, a procedural Rule-Based Expert System (RBES) using an interactive question-and-answer sequence for diagnosis of Psychiatric diseases. Descriptive questions are used primarily to describe the existence of something or process. The questionnaire itself is based on an expert systems approach, which allows selective progress through the questionnaire structure, based on responses to previous questions. The disease symptoms have to be in a specific specialism such as Psychological Anxiety, ObsessiveCompulsive disease, Hysteria disease, and Depression [16].

An expert system for diagnosis of psychiatric diseases has been developed with two approaches: Procedural ES and Declarative ES. Design of the interfaces were written procedurally while prolog programs were written for the Declarative ES.

In this paper we present an inference engine which operates by the method of backward chaining, so the backward chaining is the best reasoning technique for diagnosis problems. Prolog is an example of a backward chaining engine. Backward Chaining is a query driven (goal-driven reasoning) approach. Beginning with a dedicated query called the goal, program rules and data items are recursively selected if they are relevant for "proving" that a query succeeds. The query is then replaced by the query part (possibly consisting of a conjunction or disjunction of smaller queries) of the selected rule, and the process is repeated until all queries can be evaluated against data items in the database ("facts"). A Prolog goal has four ports representing the flow of control through the goal (Figure 2): Call, Exit, Redo, and Fail. Prolog debuggers use these ports to describe the state of a query [17].

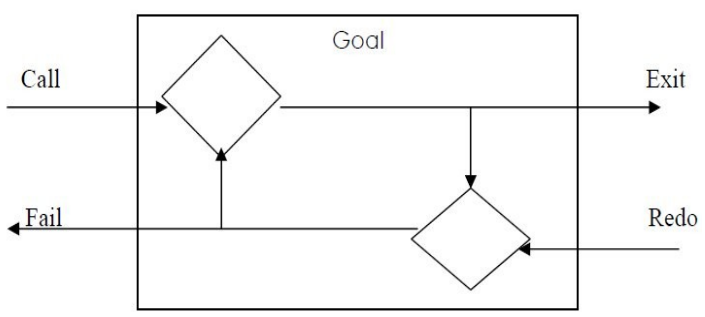

Figure 2: The ports of a Prolog goal

The explanation facility of the expert system provides a mechanism for querying the context for getting the value of a variable (what?) and knowing how a fact is established (how?) [18].

\section{SYSTEM DESIGN}

The proposed system has been designed in two ways: descriptive and procedural. The Figure 3 . describes the components of the proposed online Rule-Based Expert System. 


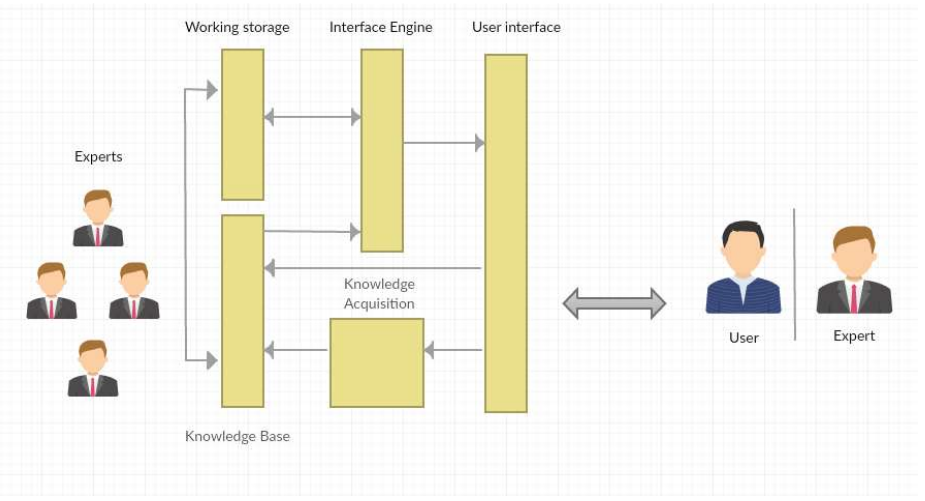

Figure 3: The proposed knowledge-based expert system structure

In this context, we can define the functions and roles of the main elements of the expert system as a framework that manages information dynamically by the integration of dedicated analysis tools. The tools to be used in any particular situation are chosen by special modules that reason about the best algorithms to use according to the information type and features. The reasoning part may be created using current Artificial Intelligence concepts and subsequently incorporated in the expert system which may also include workflows as an elementary module, as expert system techniques have matured into a standard information technology, the most important recent trend is the increasing integration of this technology with conventional information processing [19].

Here in brief we will explain the components of the expert system as follows:

The Knowledge Base (KB) contains the domain knowledge useful for problem solving. Each rule specifies a relation, recommendation, directive, strategy, heuristics. IF (condition) THEN (action) - When the condition part of the rule is satisfied, the rule is said to fire and the action part is executed. The Database includes a set of facts used to match against the IF (condition) parts of the rules stored in the knowledge base. The Inference Engine caries out the reasoning whereby the expert system reaches a solution. It links the rules given in the knowledge base with the facts provided in the database. The inference engine is a generic control mechanism for navigating through and manipulating knowledge and deduce results in an organized manner.

The User Interface controls the dialog between the user and the system. The process of Knowledge Acquisition is accomplished through iterations: based on feedback both from the expert and from potential users of the expert system. Performed by the knowledge engineers. The problem data stored as facts in Working Storage [19].

\subsection{DeClarative Method}

Declarative programming often considers programs as theories of a formal logic, and computations as deductions in that logic space. Declarative programming has become of particular interest recently, as it may greatly simplify writing parallel programs [17].

Once again it should be emphasized that presented in Figure 4 structure contains only the necessary minimum, which means the mandatory presence of the elements indicated on it; If the system is presented by developers as an expert, it guarantees the availability of a knowledge processing apparatus. However, the medical ES can be significantly more difficult and additionally include databases, data exchange interfaces with various application packages, electronic libraries, etc. 


\subsubsection{EXPERT SYSTEM SHELL}

The shell is a piece of software which contains the user interface, a format for declarative knowledge in the knowledge base, and an inference engine. The knowledge engineer uses the shell to build a system for a particular problem domain. An expert system shell (declarative) support environment should as a minimum include the following: User Interface, Inference Engine and Knowledge Base.

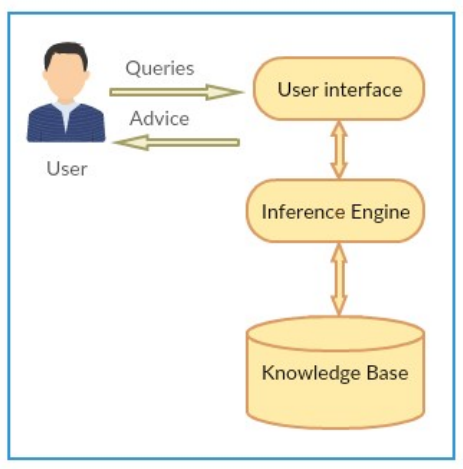

Figure 4: Declarative Expert System

\subsection{Procedural Method}

Figure 5 shows procedural online Expert System development cycle in the form of a flow chart including problem definition, conceptual design, prototyping, system development, implementation, testing and evaluating.

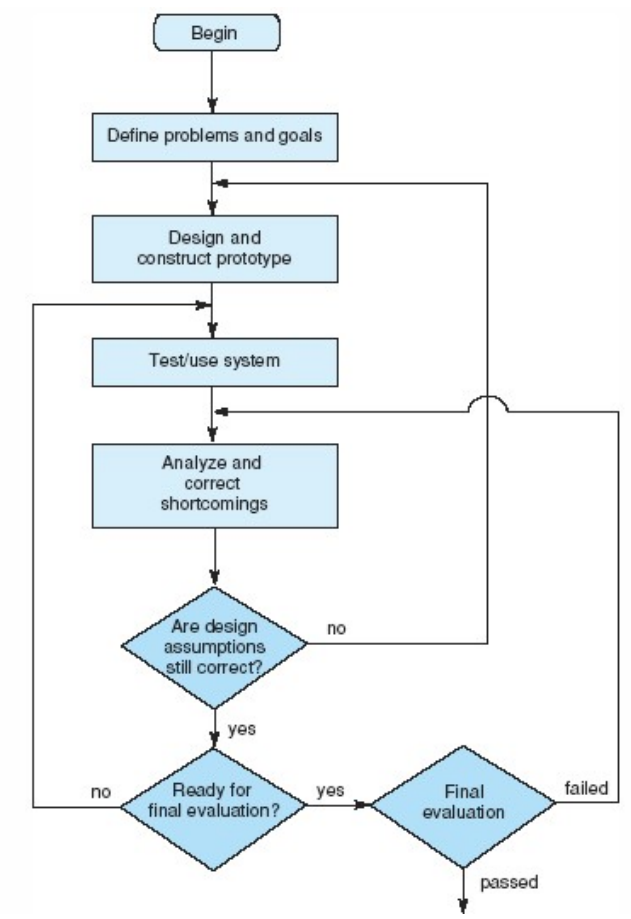

Figure 5: Flow chart of ES development cycle 


\subsection{PSYCHIATRIC SYMPTOMS AND DiSEASES}

We listed all the popular psychological symptoms (about 23 symptoms) and sorted them by their importance. The list of symptoms is illustrated in Table1. This importance was determined by the doctors at Mental Hospital Qassim (e.g. how often the symptom is observed by a patient suffering from a certain psychological disease). In the same way, we listed the diseases that depend on the previous symptoms. Some examples of Psychological Diseases are shown in Table2. After sorting, the most important combinations of the most important symptoms were formed.

Table 1: Symptoms

\begin{tabular}{|c|c|}
\hline$I D$ & Symptoms \\
\hline 1 & The fatigue \\
\hline 2 & Feeling muscle tension. \\
\hline 3 & Hyperhidrosis \\
\hline 4 & The confusion \\
\hline 5 & Insomnia and difficulty of sleep \\
\hline 6 & Abdominal pain \\
\hline 7 & Nervousness or stress \\
\hline 8 & Fear of being stolen or polluted \\
\hline 9 & Fear of causing harm to others \\
\hline 10 & Fear of mistakes \\
\hline 11 & The excessive need for organization, integration and accuracy \\
\hline 12 & Showers more than once \\
\hline 13 & Hand washing frequently \\
\hline 14 & Eating a certain fixed group of food \\
\hline 15 & Total separation from reality \\
\hline 16 & Temporary loss of memory \\
\hline 17 & Absence from consciousness \\
\hline 18 & The patient's feeling of hatred toward a certain person \\
\hline 19 & Sleep and food disruption \\
\hline 20 & Inactivity in the movement of the body \\
\hline 21 & Fear and inner horror \\
\hline 22 & Constant sense of frustration and loss of hope \\
\hline 23 & Loss of enjoyment of life and lack of decision-making \\
\hline
\end{tabular}

This means that most popular clinical states would be considered. These combinations would be used as $<$ Condition $>$ in the rules. For each combination, the doctors then used their knowledge and experience to draw a conclusion about a patient. A program will browse the patient database to summarize the common syndromes that affirm or exclude a certain Psychological disease and then create new rules. 
Table 2: Symptoms and Diseases

\begin{tabular}{|c|l|l|}
\hline \multicolumn{1}{|l|}{$I D \#$} & \multicolumn{1}{|c|}{ Disease Name } & \multicolumn{1}{c|}{ Symptoms } \\
\hline 1 & Psychological anxiety & $1,2,3,4,5,6,7$ \\
\hline 2 & Obsessive-compulsive disorder & $8,9,10,11,12,13,14$ \\
\hline 3 & Hysteria & $15,16,17,18$ \\
\hline 4 & Depression & $19,20,21,22,23$ \\
\hline
\end{tabular}

\subsection{KNOWLEDGE REPRESENTATION}

Decision tables are used in the elaboration of knowledge representation. A decision table for psychiatric diseases diagnosis by their symptoms (Table 3), has one row per 'rule', one column per decision variable. An additional column for the decision to take when that rule evaluates to true.

Table 3: Decision table

\begin{tabular}{|c|c|c|c|c|c|c|c|c|c|c|c|c|c|c|c|c|c|c|c|c|c|}
\hline $\begin{array}{c}\text { Diseases } \backslash \\
\text { Symptom } \\
\text { s }\end{array}$ & 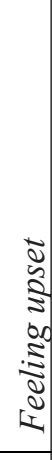 & 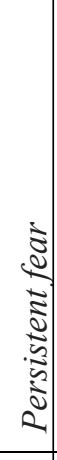 & 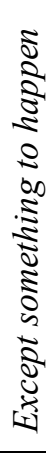 & 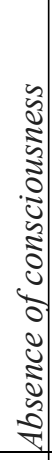 & 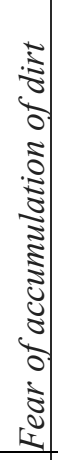 & 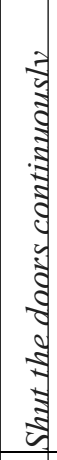 & 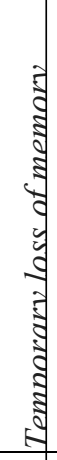 & 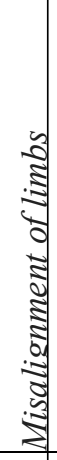 & 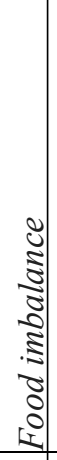 & 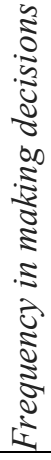 & 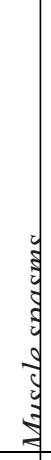 & 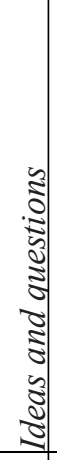 & 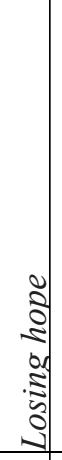 & 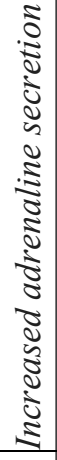 & 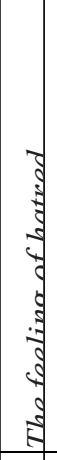 & $\begin{array}{c} \\
\\
\\
0 \\
0 \\
0 \\
0 \\
0 \\
0 \\
0 \\
0 \\
.5 \\
5 \\
0 \\
0 \\
0\end{array}$ & 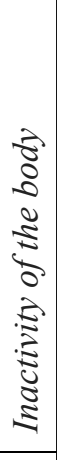 & 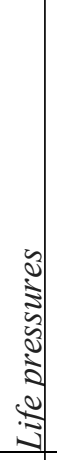 & $\begin{array}{c}5 \\
5 \\
5 \\
5 \\
\vdots \\
5 \\
0 \\
\vdots \\
0 \\
0 \\
\end{array}$ & $\begin{array}{l}5 \\
.5 \\
5 \\
5 \\
5 \\
5 \\
\vdots \\
\vdots\end{array}$ & 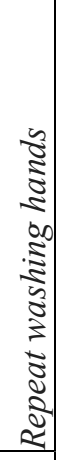 \\
\hline $\begin{array}{l}\text { Symbol of } \\
\text { Symptoms }\end{array}$ & $\overrightarrow{I I}$ & N & 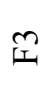 & 莸 & $n$ & $\begin{array}{l}0 \\
0\end{array}$ & $\hat{I}$ & $\begin{array}{l}\infty \\
\infty\end{array}$ & 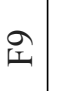 & $\stackrel{0}{\text { 도 }}$ & $\vec{Z}$ & $\frac{N}{1}$ & $\frac{m}{1}$ & $\frac{\Xi}{I}$ & $\frac{n}{1}$ & $\frac{0}{1}$ & 不 & $\frac{\infty}{\square}$ & $\frac{2}{1}$ & 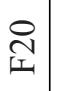 & $\overrightarrow{\mathrm{I}}$ \\
\hline $\begin{array}{l}\text { Psycholog } \\
\text { ical } \\
\text { anxiety }\end{array}$ & $\sqrt{ }$ & $\sqrt{ }$ & $\sqrt{ }$ & $x$ & $x$ & $\times$ & $x$ & $x$ & $x$ & $x$ & $\sqrt{ }$ & $x$ & $x$ & $\sqrt{ }$ & $x$ & $x$ & $x$ & $x$ & $\sqrt{ }$ & $\sqrt{ }$ & $x$ \\
\hline $\begin{array}{l}\text { Obsessive- } \\
\text { compulsiv } \\
e\end{array}$ & $x$ & $x$ & $x$ & $x$ & $\sqrt{ }$ & $\sqrt{ }$ & $x$ & $x$ & $\times$ & $\sqrt{ }$ & $\times$ & $\sqrt{ }$ & $x$ & $\times$ & $x$ & $\sqrt{ }$ & $x$ & $x$ & $x$ & $x$ & $\sqrt{ }$ \\
\hline Hysteria & $x$ & $x$ & $x$ & $\sqrt{ }$ & $x$ & $x$ & $\sqrt{ }$ & $\sqrt{ }$ & $x$ & $x$ & $x$ & $x$ & $x$ & $x$ & $\sqrt{ }$ & $x$ & $x$ & $x$ & $x$ & $x$ & $x$ \\
\hline $\begin{array}{l}\text { Depressio } \\
\mathrm{n}\end{array}$ & $x$ & $x$ & $\times$ & $x$ & $x$ & $\times$ & $x$ & $x$ & $\sqrt{ }$ & $\times$ & $x$ & $x$ & $\sqrt{ }$ & $x$ & $\sqrt{ }$ & $x$ & $\sqrt{ }$ & $\sqrt{ }$ & $x$ & $x$ & $x$ \\
\hline
\end{tabular}

The diagnostic chart shown in Figure 6 is a graphical representation or an organization chart. The purpose of the diagnostic system is to diagnose and classify the symptoms of each disease. The diagnostic chart uses simple geometric symbols and arrows to define the relationships between each disease and its appropriate symptoms. 


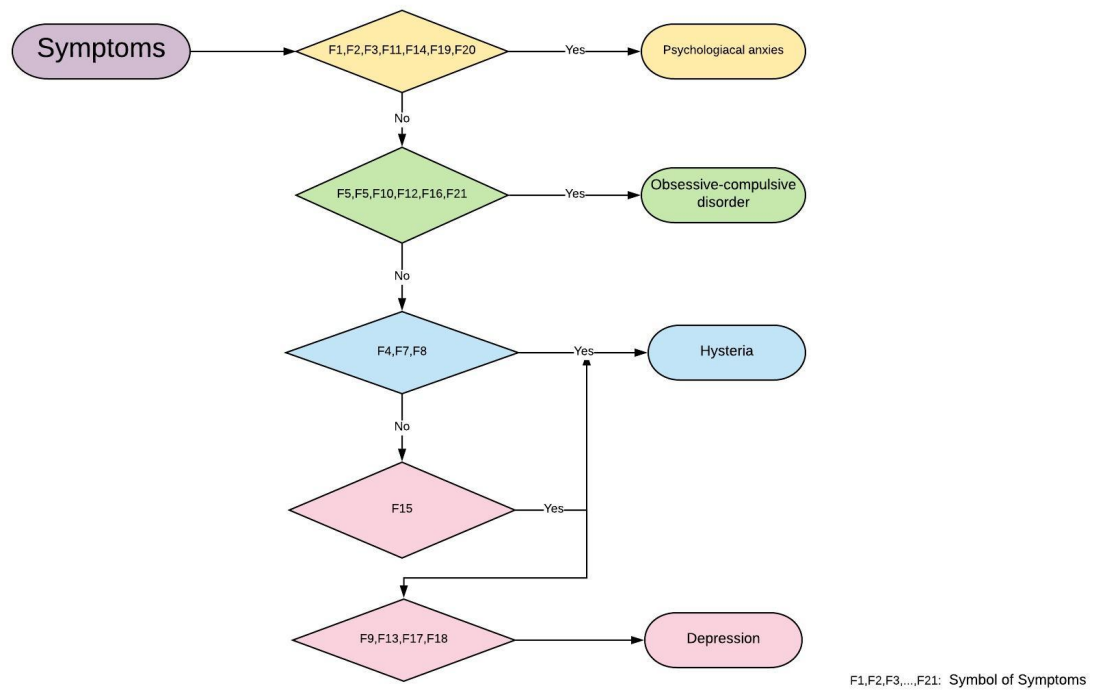

Figure 6: Diagnostic chart

\subsection{REASONING UNDER UNCERTAINTY}

One of the most famous expert systems is the MYCIN system, developed in the late seventies at Stanford University (USA). It is an upgraded version of the Bayesian updating, that was used in the kernel of the expert system The MYCIN system is an expert system designed to work in the field of diagnosis and treatment of blood poisoning and meningitis infections [18]. In an expert system with MYCIN certainty factors, the knowledge base consists of a set of rules that have the following syntax: IF <evidence> THEN <hypothesis> \{cf\}. Where, a cf represents belief in hypothesis $\mathrm{H}$ given that evidence $\mathrm{E}$ has occurred. In order to calculate the MYCIN certainty factor combined these weights using the formula (1) to yield a single certainty factor:

$$
\operatorname{cf}(\mathrm{x}, \mathrm{y})=\left\{\begin{array}{lr}
\mathrm{X}+\mathrm{Y}-\mathrm{XY} & \text { if } \mathrm{X}>0 \text { and } Y>0 \\
\frac{X+Y}{1-\min [|X|,|Y|]} & \text { if }(X \times Y)<0 \\
X+Y+X Y & \text { if } X<0 \text { and } Y<0
\end{array}\right\}
$$

Where $\mathrm{X}$ and $\mathrm{Y}$ are the confidence in hypothesis $\mathrm{H}$ establish by Rule $1 \& 2$, respectively [20]. For example, suppose $\operatorname{cf}(\mathrm{E} 1)=\operatorname{cf}(\mathrm{E} 2)=1.0$, Then, $\mathrm{X}(\mathrm{H}, \mathrm{E} 1)=\operatorname{cf}(\mathrm{E} 1) * \mathrm{X}=1.0 \times 0.8=0.8$ $\mathrm{Y}(\mathrm{H}, \mathrm{E} 2)=\operatorname{cf}(\mathrm{E} 2) * \mathrm{Y}=1.0 \times 0.6=0.6$.

We obtain, $\operatorname{cf}(\mathrm{x}, \mathrm{y})=\mathrm{X}(\mathrm{H}, \mathrm{E} 1)+\mathrm{Y}(\mathrm{H}, \mathrm{E} 2) *[1-\mathrm{X}(\mathrm{H}, \mathrm{E} 1)]=0.8+0.6 *(1-0.8)=0.92$ Suppose the knowledge base consists of the following rules:

Rule 1: IF

Rule 2: IF
A is a1

THEN $\mathrm{C}$ is $\mathrm{c} 1\{\mathrm{cf} 0.8\}$

$\mathrm{B}$ is $\mathrm{b} 1$

THEN $\mathrm{C}$ is $\mathrm{cl}\{\mathrm{cf} 0.6\}$ 


\section{IMPLEMENTATION}

The proposed KBES was designed to manage the knowledge such as creating, updating and editing the facts of users and doctors. The authors have been used different software modules, like: freely available SWI Prolog interpreter for declarative ES [21]. For online procedural ES, the codes being worked on "notepad++", which includes several programming languages such as using PHP, MySQL, HTML, JavaScript and CSS language, were integrated to develop the procedural online ES shell model [22]. Validity of software was checked, e.g. data being acquired through various sources.

\section{EXPERIMENTAL RESULTS}

Two main Prolog programs were written: The first was written based on earlier types of psychological diseases and its symptoms also the relationship of the doctor with the patient (Figure 7). The second program was written for an Expert System Shell (Figure 8). Figure 9 shows SWI Prolog-Trace in action.

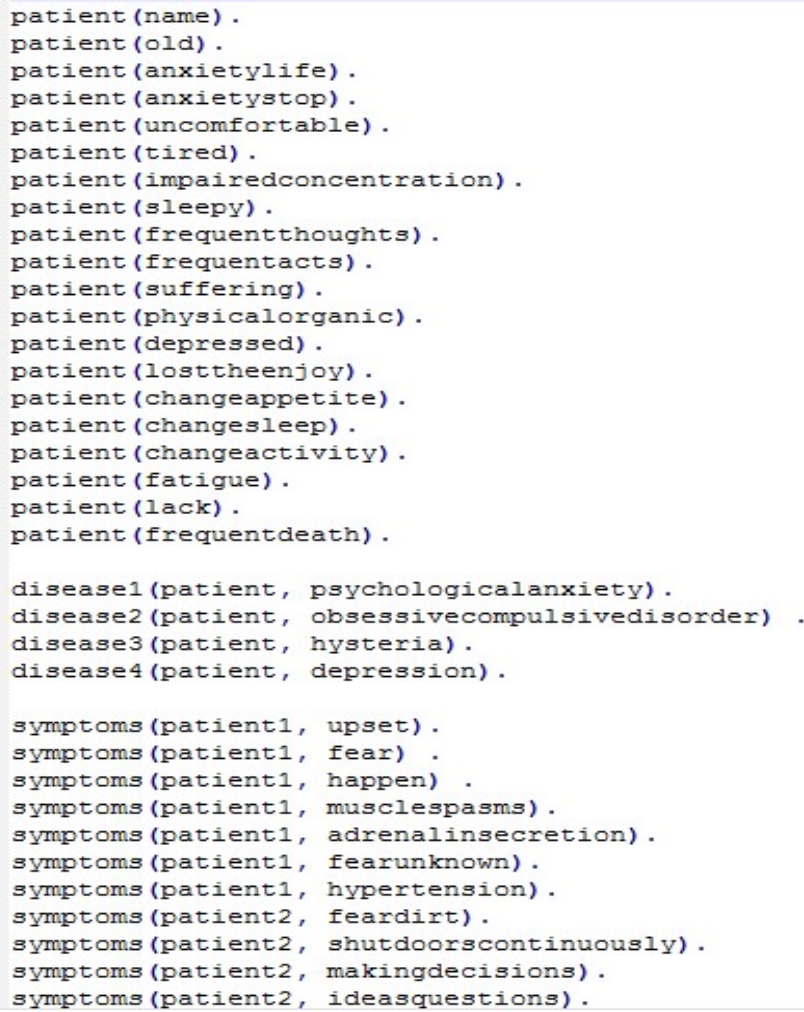

Figure 7: SWI Prolog program 
go: -welcome, help.

welcome: -

write(' WELCOME TO PSYCHOLOGICAL EXPERT SYSTEM '), nl.

help:-

write('What is the name of the patient?'), nl, $\operatorname{read}(\mathrm{NN})$,

write('Peace be upon you'),

write('Type your gender?'), nl, $\operatorname{read}(\mathrm{GG})$,

write('What is your age?'), nl, $\operatorname{read}(\mathrm{AA})$,

write (' -.....................

write('diseases available on the system are: '), nl,nl,

write('Psychological Anxiety, Obsessive Compulsive, Hysteria, Depression'), nl,

write('Diseases name_report. Show all symptoms available.'),nl, write('Symptom_no(symptom,disease name)

write(' - .

psychologicalAnxiety $(\mathrm{X})$ : - $\operatorname{symptoma}(\mathrm{X})$.

symptoma( $\mathrm{X}$, psychologicalAnxiety).

symptoma(' 1 -The fatigue').

symptoma('2-Feeling muscle tension').

symptoma( ' 3 -Hyperhidrosis').

symptoma ('4-The confusion').

symptoma(' 5 -Insomnia and difficulty of sleep').

symptoma('6-Abdominal pain').

symptoma('7-Nervousness or stress').

psychologicalAnxiety_report:-

write('know symptoms are :'), nl,

psychologicalAnxiety $(\mathrm{X})$,

write (x), nl,fail.

Figure 8: Expert system shell Prolog program

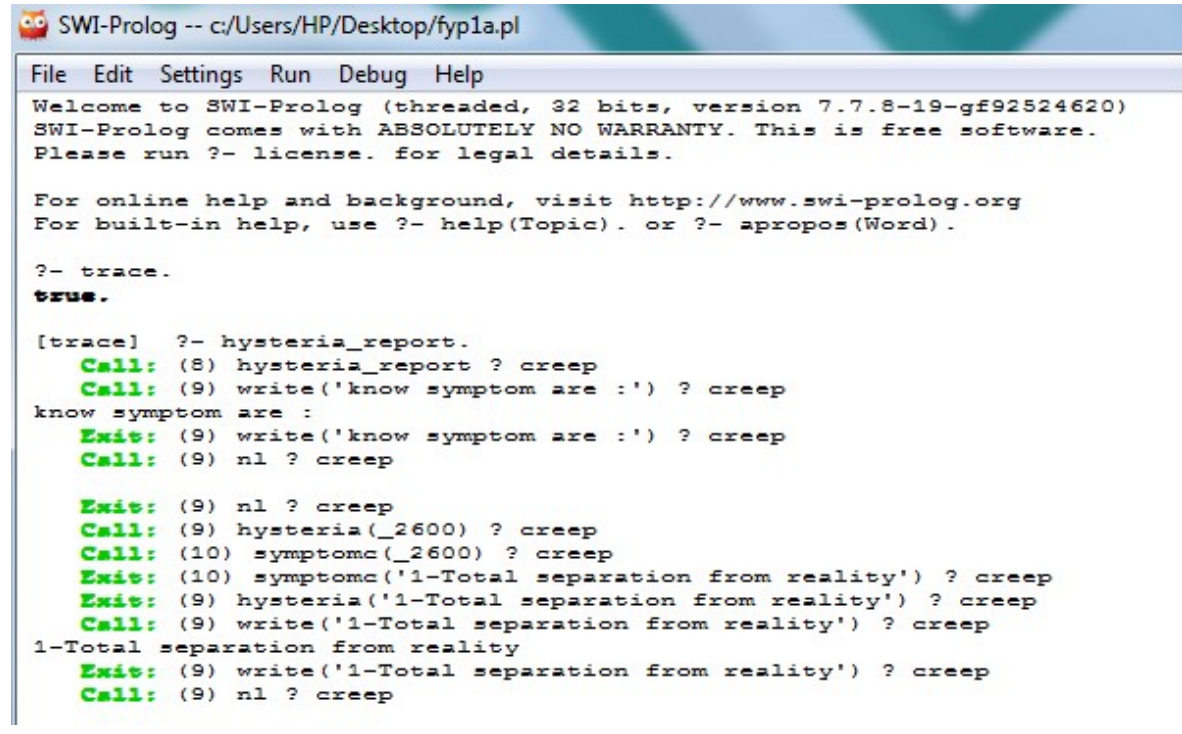

Figure 9: Trace in action

Following figures were some of the developed online KBES graphical user interface (GUI) snapshots. For example, Figures 10,11 show the home page and login screen of the procedural KBES respectively. When you navigate the website through the link: http://esp-online.site/, you can discover more interesting patterns and features for both the user and the doctor: Registration form, contact information, diagnosis and result page,...etc. 


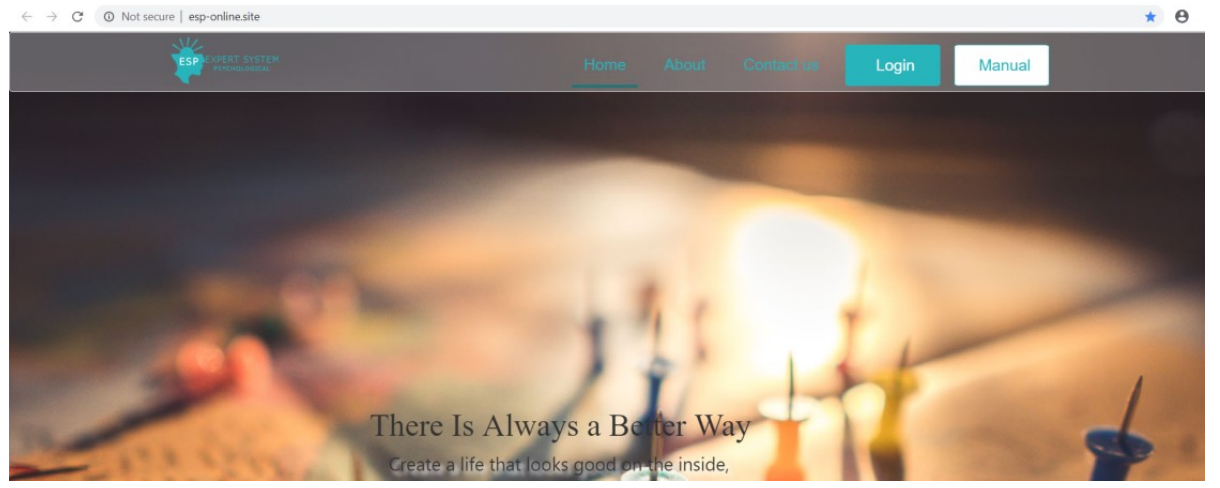

Figure 10: Home page

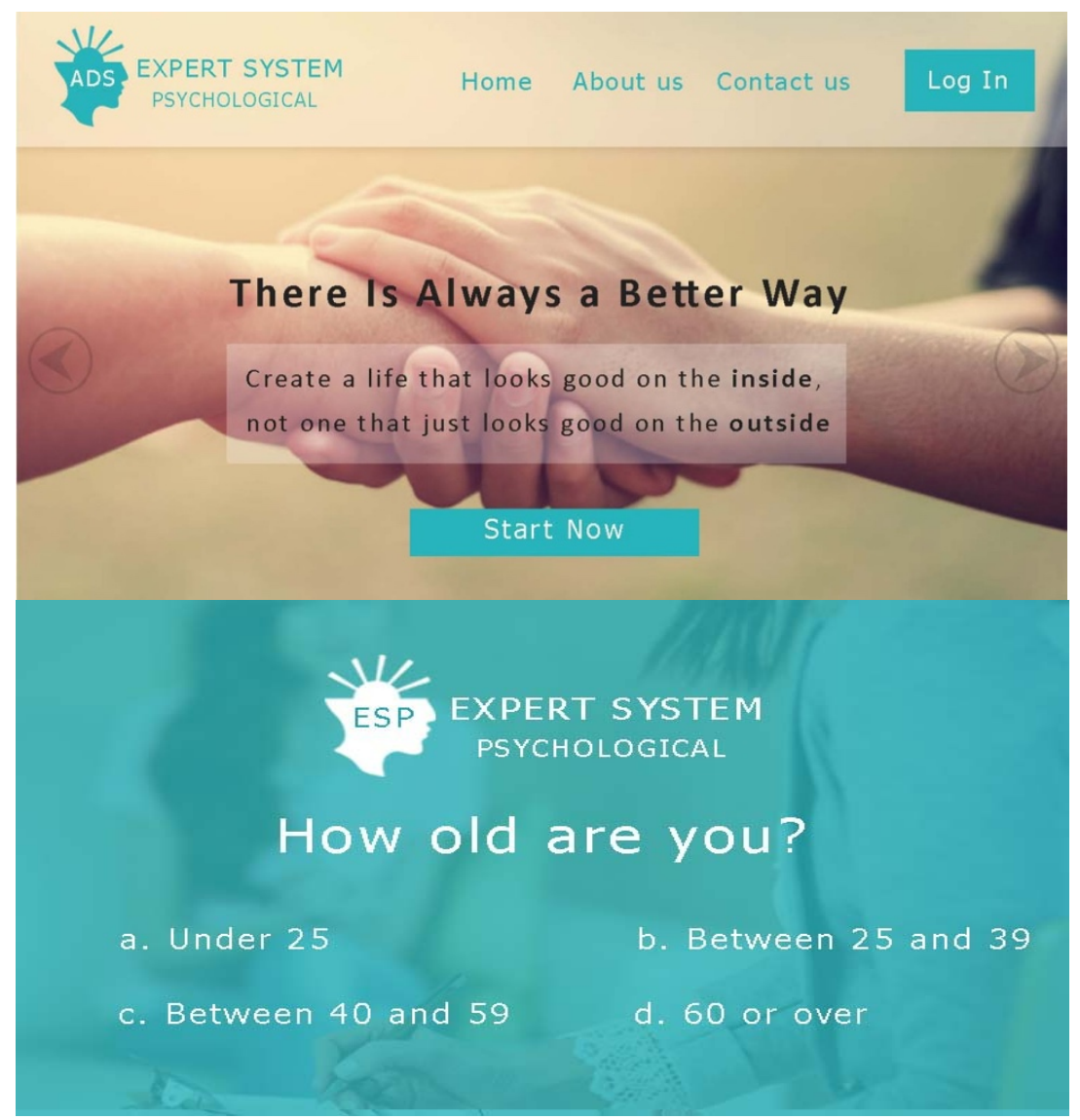

Figure 11: Login screen (patient and doctor)

The Figure 12 shows a sample diagnostic screen showing the disease name, the certainty factor, definition, where we distinguish therapy button, that takes us to a detailed report page on the diagnosed disease. 


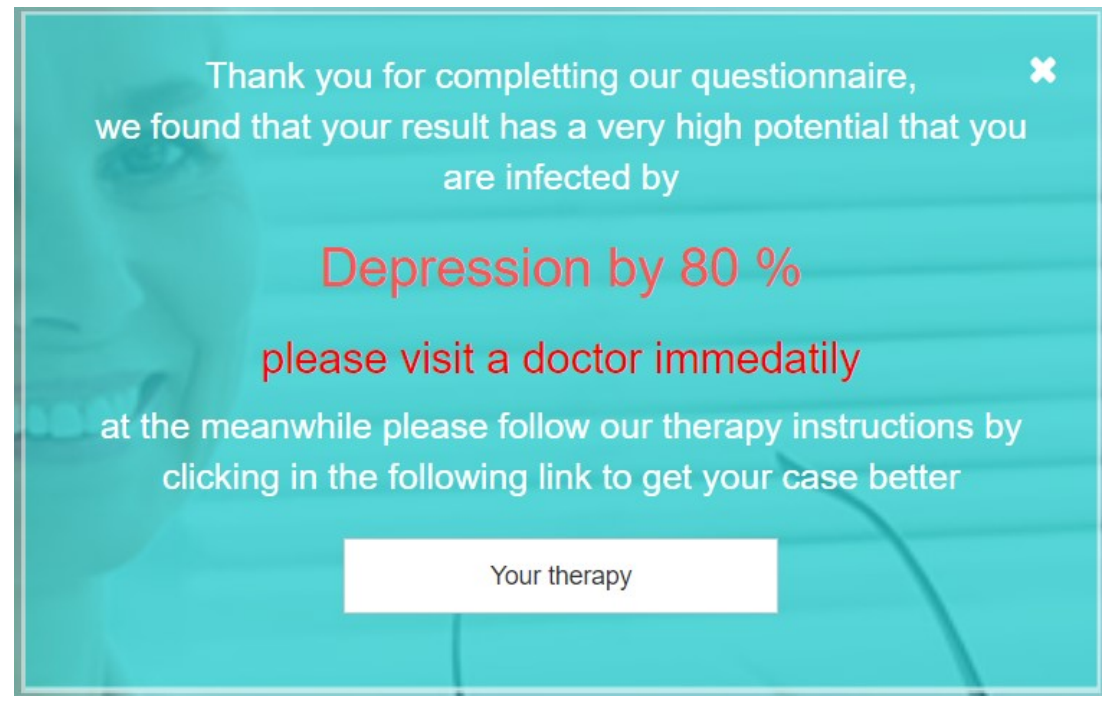

Figure 12: Result Screen

\section{CONCLUSION}

In this paper, declarative and an online procedural rule-based expert system models for psychological diseases diagnosis and classification were developed. The constructed system exploited computer as an intelligent and deductive tool. In this work, we have combined the benefits of Internet technology and the expert system shell. We aspire to develop and expand the services available on the Internet to psychological patients appropriately. The field of online medical experts is large and extensive, so we have a strong motivation to work on this kind of research aimed at serving psychological patients. However, the expert systems that address this type of mental illness is relatively less than others, this is one of the important points of our paper. Since the proposed expert system is a decision support tool for the right diagnosis making by the psychiatrist, the MYCIN-type uncertainty factor has been taken into account like to the Fuzzy logic. It is noted that the uncertainty factor of the declarative rulebased expert system model, appears in the form of diagnostic accuracy rate of an online procedural rule-based expert system model for different types of psychiatric diseases. The web-based expert system model can be used also as a database and archiving tool by the doctor, where the site has features beyond the psychological diseases diagnosis, can be easily detected by any observer. On future work we aim to make the diagnosis more reliable. Also, we can enhance our website to add more other types of psychiatric disorders to the knowledge base.

\section{ACKNOWLEDGEMENTS}

We would like to extend our thanks to the doctors and medical staff at Mental Hospital Qassim for their contribution and support in the mental illness information.

\section{REFERENCES}

[1] ICD-10 Version:2016 -World Health Organization: https://icd.who.int/browse10/2016/en\#/F41.2

[2] Luciano CominNunes, Plácido Rogério Pinheiro, Tarcísio Cavalcante Pequeno, “An Expert System Applied to the Diagnosis of Psychological Disorders", Conference Paper, December 2009 DOI: 10.1109/ICICISYS.2009.5358164, Source: IEEE Xplore. 
[3] Durkin, John. "Expert System: Design and Development," New York: Macmillan Publishing Company, Inc., 1994.

[4] TMRF e-Book Advanced Knowledge Based Systems: Model, Applications \& Research (Eds. Sajja \& Akerkar), Vol. 1, pp $50-73,2010$.

[5] Ivan Bratko, PROLOG Programming for Artificial Intelligence, 2000, ISBN 0-201-40375-7.

[6] Al-Hajji, Ahmad A. "Rule-Based expert system for diagnosis and symptom of neurological disorders "Neurologist Expert System (NES)"." In Proceedings of the 1st Taibah University International Conference on Computing and Information Technology, Al-Madinah Al-Munawwarah, Saudi Arabia, vol. 1214, p. 6772. 2012.

[7] Komal R. Hole, Vijay S. Gulhane, Rule-Based Expert System for the Diagnosis of Memory Loss Diseases, IJISET - International Journal of Innovative Science, Engineering \& Technology, Vol. 1 Issue 3, May 2014.

[8] Diagnostic and Statistical Manual of Mental Disorders - Fourth Edition (DSM-IV), American Psychiatric Association, Washington D.C., 1994.

[9] International Statistical Classification of Diseases and Related Health Problems, 10th Revision, Chapter 5: Mental Disorders, Geneva, World Health Organization, 1992.

[10] Jeste D. Press Interview. Cited by Mary Ellen Schneider in Five ways the DSM 5 could change your practice. Clin Psychiatry News. 2013:41.

[11] Dr. D.K. Sreekantha, T.M. Girish and Dr. R.V.Kulkarni (2015), knowledgebase systems in neuro science- A study, International Journal on Soft Computing, Artificial Intelligence and Applications (IJSCAI), Vol.4, No.2, May 2015.

[12] Badri Adhikari, Md. Hasan Ansari, Priti Shrestha and Susma Pant (September 25, 2008) "Neurology Diagnosis System", Module

[13] Borgohain, Rajdeep, and Sugata Sanyal. "Rule based expert system for diagnosis of neuromuscular disorders." arXiv preprint arXiv: 1207.2104 (2012)

[14] Luciano Comin Nunes, Plácido Rogério Pinheiro, Tarcísio Cavalcante Pequeno, An Expert System Applied to the Diagnosis of Psychological Disorders, DOI: 10.1109/ICICISYS.2009.5358164 • Source: IEEE Xplore

[15] Zaharia Mihai Horia, AI Applications in Psychology, Expert Systems for Human, Materials and Automation, InTech, 2011, ISBN 978-953-307-334-7 (book chapter).

[16] American Psychiatric Association: Diagnostic and Statistical Manual of Mental Disorders,4th ed, revised (DSM-IV-TR). Washington, DC, American Psychiatric Association

[17] Ivan Bratko, PROLOG Programming for Artificial Intelligence, 2000, ISBN 0-201-40375-7.

[18] Gulankong, Dong-Ling $\mathrm{Xu}$ and Jian-Bo Yang, Clinical Decision Support Systems: A Review on Knowledge Representation and Inference under Uncertainties, International Journal of Computational Intelligence Systems, Vol.1, No. 2 (May, 2008), 159-167.

[19] Michael Negnevitsky. "Artificial intelligence: A Guide to Intelligent Systems”, 3rd Edition, Pearson Educational Limited, 2007.

[20] Book: Knowledge-Based Systems,1st Ed. Jones and Bartlett Publishers, Inc., USA C2009 ISBN:0763776475 9780763776473. 
[21] SWI-Prolog reference manual: http://www.swi-prolog.org/pldoc/doc for?object=manual

[22] Michele E. Davis and Jon A. Phillips, Learning PHP and MySQL, Copyright (C) 2007, 2006 Michele E. Davis and Jon A. Phillips. All rights reserved.Printed in the United States of America.,Published by O’Reilly Media, Inc., 1005 Gravenstein Highway North, Sebastopol, CA 95472

\section{AUTHORS}

Dr. Ahmad A. Al-Hajji is an Associate Professor in Computer Science Department, College of Science \& Arts in Al-Bukairyah, Qassim University, Saudi Arabia. He received the B.Sc. (Eng.) degree in Electrical and Electronic Engineering from University of Aleppo 1986, his M.Sc. and Ph.D. degrees in "Automation and Computer Systems” from Odessa National Polytechnic University ONPU, Ukraine, in 1990 and 1993, respectively. He worked in different universities and countries. His research interests include Simulation and Modelling, Artificial Intelligence, ANNs, Expert Systems and Optimization Techniques.

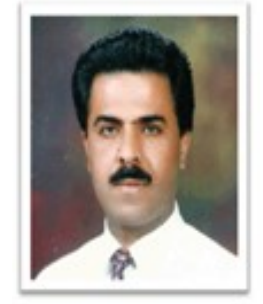

Fatimah M. AlSuhaibani is a graduate student in the Department of Computer Science, College of Science and Arts, Al-Bukairyah. Qassim University, Saudi Arabia.

Nouf S. AlHarbi is a graduate student in the Department of Computer Science, College of Science and Arts, Al-Bukairyah. Qassim University, Saudi Arabia. 